\title{
EDUCAÇÃO SEMIPRESENCIAL (A DISTÂNCIA) E PRESENCIAL: MOBILIDADE ACADÊMICA E INTEGRAÇÃO DA EDUCAÇÃO SUPERIOR NO ESTADO DO RIO DE JANEIRO
}

\author{
Zacarias Gama | zacarias_gama@yahoo.com.br \\ Coordenador e conteudista da disciplina Métodos e Técnicas de Avaliação (MTA) do Consórcio CEDERJ. Professor do Programa de \\ Pós-graduação em Políticas Públicas e Formação Humana e integrante do Departamento de Políticas Públicas, Avaliação e Gestão da \\ Educação (DEPAG) da Faculdade de Educação da Universidade do Estado do Rio de Janeiro
}

\section{Resumo}

O ponto de partida para a elaboração do presente texto foi a Deliberação CEA n 04 de 14 de dezembro de 2009, que institui e regulamenta a mobilidade acadêmica e a integração de alunos dos cursos de EAD oferecidos pelo Consórcio CEDERJ e alunos presenciais das universidades consorciadas. O objetivo foi o de apreender a sua essência, situando-a no contexto da revolução global de reforma da administração pública, dar visibilidade à contradição que encerra, assim como às mediações que determinam seus movimentos e direções.

\section{Palavras-chave}

Educação superior. Educação semipresencial e presencial. Políticas públicas. Capitalismo competitivo. Espaço integrado de mobilidade acadêmica. Integração de educação superior. 
SEMI-PRESENTIAL (DISTANCE) AND CLASSROOM EDUCATION: ACADEMIC MOBILITY AND HIGHER EDUCATION INTEGRATION IN RIO DE JANEIRO STATE

\section{Abstract}

The starting point for this text was CEA Determination No. 04 dated December 14, 2009, which establishes and regulates the academic mobility and integration of students in distance education courses offered by the CEDERJ Consortium and classroom students in the consortium universities. The goal was to apprehend its essence, placing it in the context of the global revolution in public administration reform, and bring to light the contradiction it embodies, as well as the mediations that determine its movements and directions.

\section{Keywords}

Higher education. Semi-distance and classroom learning. Public policies. Competitive capitalism. Integrated space of academic mobility. Higher education integration.

\section{Introdução}

A Fundação Centro de Ciências e Educação Superior a Distância do Estado do Rio de Janeiro (CECIERJ/ CEDERJ), por meio de ato de seu Conselho de Estratégias Acadêmicas, divulgou deliberação que institui e regulamenta a mobilidade acadêmica $e$ a integração de alunos dos cursos de modalidade semipresencial oferecidos pelo Consórcio CEDERJ ${ }^{1}$ e presenciais das universidades consorciadas (Deliberação CEA n ${ }^{\circ} 04$ de 14 de dezembro de 2009), já devidamente publicada em Diário Oficial para imediata entrada em vigor.

Tal Deliberação, que faculta aos alunos das universidades consorciadas a possibilidade de cursar disciplinas isoladas, semipresenciais ou não, apresenta-se, simultaneamente, como poderoso instrumento de promoção da mobilidade acadêmica e de integração interinstitucional no estado do Rio de Janeiro. É um primeiro passo extremamente significativo para a integração dos alunos do sistema de educação pública superior.

A tal deliberação, porém, deverão suceder outra e outras que em um futuro muito próximo visarão a consolidação de um autêntico Espaço Integrado de Mobilidade Acadêmica e Educação Superior do estado do Rio de Janeiro. Essa predição não é mágica nem resulta de qualquer prática de necromancia; muito pelo contrário. Ela visa situar essa Deliberação no quadro das reformas universitárias e da reconfiguração do estado que vêm sendo processadas nesta primeira década do século XXI no Brasil e em diversas partes do mundo.

Em face da realidade em processo inicial de construção mas já com meios, fins, instrumentos, exigências e esforços, é natural que os indivíduos pautados pelo senso comum possam intuitivamente criar representações positivas a respeito da mesma. Aliás, como Kosik salienta (1976, p. 14)², a práxis utilitária imediata e o senso comum, embora permitam ao homem orientar-se no mundo, familiarizar-se com as coisas e manejá-las, não lhe proporcionam, entretanto, a compreensão das coisas e da realidade. Toda essa orientação, familiarização e manejo das coisas são superficiais, fetichizadas e pertencentes ao mundo da pseudoconcreticidade, no qual reina "um claro-escuro de verdade e engano".

O fenômeno social no nosso caso, a integração e a mobilidade acadêmica interinstitucional de alunos entre as modalidades semipresenciais e presenciais instituídos e regulamentados pela Deliberação CEA no 04 de 14 de dezembro de 2009, ainda com base em Kosik (1976, p. 15), "indica algo que não é ele mesmo". Sua essência, assim como a de outros fenômenos, não nos é dada imediatamente; para ser apreendida é necessário um esforço metodológico considerável. O método da economia política, tal como foi desenvolvido por Marx, é de grande importância em nosso esforço de apreender a sua essência; da mesma forma, são as duas categorias metodológicas inerentes ao método: totalidade e contradição.

A totalidade, do ponto de vista epistemológico, além de nos permitir uma compreensão em bases científicas, é um apelo, como ressalta Moura (1977, p. 114) ${ }^{3}$ "à necessária consideração de todos os elementos do fenômeno" (ou do Universo) na medida em que constitui uma unidade estruturada de acordo e por intermédio de conexões objetivas, suscetíveis de irem sendo apercebidas e determinadas". É essa compreensão que nos leva a abordar o fenômeno na sua imediatidade como parte do real "como fixação de um 
seu determinado momento", e a situá-lo "no processo totalizante de desenvolvimento em que se inscreve".

A contradição, por sua vez, nos ajuda a apreciar o movimento e a mudança, não a partir de misteriosas ou de milagrosas intervenções sobrenaturais, mas como resultado do desenvolvimento das diferentes contradições que, historicamente, também se vão constituindo no interior da própria órbita da realidade objetiva (MOURA, 1977, p. 140). Por essa razão, a mobilidade acadêmica e a integração interinstitucional no estado do Rio de Janeiro, na perspectiva dessa categoria, têm de ser analisados no seu movimento, no seu processo de transformação e nas suas deslocações.

Nosso objetivo central no presente texto é, então, o de examinar tal Deliberação em sua totalidade e em suas conexões, a fim de dar visibilidade às contradições e mediações que contém no sentido de compreender a mudança e o movimento que realiza, entendendo que uma definição rigorosa das forças estruturantes da mobilidade acadêmica e integração da educação superior semipresencial e presencial, é importante para uma prática social que, com eficácia, possa ser organizada e materializada.

\section{Deliberação e totalidade}

A deliberação em pauta, como já dissemos, regulamenta a mobilidade acadêmica entre as modalidades semipresenciais e presenciais e dos cursos do Consórcio CEDERJ, facultando aos discentes da modalidade semipresencial a possibilidade de cursar disciplinas isoladas "na modalidade semipresencial e presencial (das universidades consorciadas) como mecanismo de promoção da mobilidade acadêmica e integração interinstitucional no Estado do Rio de Janeiro". A mesma possibilidade é válida para os discentes dos cursos da modalidade presencial; também eles poderão cursar disciplinas isoladas a distância oferecidas pelas instituições consorciadas. As coordenações dos cursos semipresenciais e presenciais se encarregarão de divulgar a lista de disciplinas oferecidas e o número de vagas disponíveis nas universidades presenciais e nos diferentes polos de educação semipresencial, mais conhecidos como polos de educação a distância.

É, então, natural que os indivíduos pautados pelo senso comum possam intuitivamente criar representa- ções positivas a respeito desta deliberação. De fato, à primeira vista, quem poderia discordar das "boas intenções" presentes na formação de um autêntico Espaço Integrado de Mobilidade Acadêmica e Educação Superior do Estado do Rio de Janeiro colocando à disposição dos alunos todas as instituições públicas de educação superior, não importando serem presenciais ou semipresenciais? Quem seria capaz de reagir a esta verdadeira reengenharia que disponibiliza aos usuários/consumidores o que procuram querendo agregar valor às suas formações acadêmicas? Nas suas aparências mais externas, tudo indica que os alunos somente têm a ganhar com o enriquecimento curricular e convívio social e cultural nos diversos campi universitários presenciais e semipresenciais existentes no estado.

Contudo, despidos de senso comum precisamos estar alertas e superar o claro-escuro de verdade e engano presentes na manifestação externa do fenômeno, do qual nos fala Kosik. Além do mais, também sabemos que "nenhuma política começa por vontade própria: por trás de cada reforma sempre há um poderoso imperativo político a empurrá-la adiante" (KETTL, 2006, p. 76) ${ }^{4}$. De mais a mais, têm sido características desta primeira década do milênio as tentativas de reinvenção do Estado, com os seus reformadores, da Coreia ao Brasil e de Portugal à Nova Zelândia, sendo pautados pela ideia de um Estado mais barato e mais eficiente para a maior realização do sistema de capital.

A categoria totalidade, em sua perspectiva metodológica, é assim de grande importância se queremos ir além da pseudoconcreticidade dos fenômenos, na medida em que sempre nos impõe um apelo de desprezo à sorte $e$ ao acaso que poderiam dispersar $e$ isolar os fenômenos. É ela que nos leva a preterir as arbitrariedades e as ocasionalidades na irrupção dos fenômenos sociais; a questionar, portanto, a edição desta deliberação como fato isolado, desligado ou simplesmente tomado como fato original produzido pelo Conselho de Estratégias Acadêmicas do CEDERJ; e a dar visibilidade à "multiplicidade de estruturas de totalidade que da análise do processo real vai resultando" (MOURA, 1977 p. 114).

Ketll (2006) do mesmo modo nos fala de uma revolução global pela reforma da administração pública observando que desde os primeiros anos da década 
de 1980 cresce em todo o mundo uma onda global de reforma do setor público, muito embora pouco se saiba sobre suas causas: "Em todo o mundo, os cidadãos e seus representantes eleitos parecem simplesmente ter chegado à conclusão de que o governo de seu país, seja de que tamanho for o seu tamanho relativo, é grande demais e precisa ser diminuído."

As objetivações de reformas em diversas partes do mundo na mesma linha desta Deliberação do CEA nos permitem, de imediato, retirá-la de seu isolamento e aparente pioneirismo e situá-la no contexto das reformas da educação superior que vêm sendo feitas no Brasil, na América Latina e na Europa. Para comprovar o que estamos afirmando, citamos a seguir diversas iniciativas de igual teor em curso no Brasil, na América Latina e na Europa.

A primeira e mais recente, bastante alardeada pela mídia, é o Novo Exame Nacional do Ensino Médio, cuja mais atual reformulação promovida pelo Ministério da Educação do Brasil deverá aumentar consideravelmente a mobilidade de alunos entre estados, atraídos pelos melhores cursos e instituições de Ensino Superior e, também, pelas promessas de bolsas pagas pelo Governo Federal para estimular a mobilidade interestadual e interinstitucional (SPINELLI, 2009) ${ }^{5}$.

O "Programa ANDIFES de Mobilidade Acadêmica" é outra ação que envolve os alunos dos cursos de graduação de Instituições Federais de Ensino Superior brasileiras; os participantes desse programa criam vínculos temporários com as IFES que os recebem como alunos matriculados em determinadas disciplinas, de acordo com a disponibilidade de vagas oferecidas (ANDIFES, 2010) ${ }^{6}$.

O Setor Educacional do Mercosul de igual modo vem desenvolvendo o projeto "Mobilidade Acadêmica para Cursos Credenciados (MARCA)", tendo em vista o intercâmbio de alunos, docentes, pesquisadores e gestores de instituições de educação superior (Mercosur Educativo, 2010) ${ }^{7}$.

Os esforços da União Europeia para a construção de uma "Europa do Conhecimento" é outra reforma já em sua fase de consolidação, justificando-se como fator indispensável ao crescimento social e humano da Europa e como componente basilar para a consolidação e o enriquecimento da cidadania europeia no terceiro milênio. Por conta da especificidade do Velho Continente, a reforma da gestão universitária e do Ensino Superior é mais abrangente, dada a necessidade de introduzir o regime de créditos em todas as universidades dos países integrantes da União Europeia, por mais seculares que sejam suas culturas $e$ universidades, muitas das quais ainda com regimes anuais de estudo. A ênfase na mobilidade dos estudantes como outro desafio é tida como imprescindível à consolidação da cidadania europeia, empregabilidade e desenvolvimento em geral.

Mais recentemente entre nós, vale citar a reforma que se desenvolve a partir da recém-criada Universidade Federal de Integração Latino-Americana (UNILA), à expensa do Governo do Brasil e com reitoria em Foz do Iguaçu. No Informativo da Comissão de Implantação da Universidade Federal da Integração Latino-Americana, a entrevista concedida pelo Prof. Gilvan Müller de Oliveira $(2009)^{8}$, professor da UFSC e consultor de organismos nacionais e internacionais em defesa do multiculturalismo e do plurilinguismo, e um artigo do Prof. Sérgio Mascarenhas (2009) ${ }^{9}$, fundador da embrapa, explicitam os imperativos políticos que empurram adiante a pretensão da universitária em curso.

Oliveira dá grande importância ao acordo entre Argentina, Uruguai e Brasil que prevê a mobilidade de estudantes entre os três países, qualificando-os como "consumidores de bens culturais na respectiva língua", e desejando tornar aqueles países cada vez mais bilíngües. Em sua ótica a integração proporcionada pela UNILA dá materialidade a um mercado de bens culturais, vendáveis e consumíveis.

Mascarenhas, por sua vez, em artigo no qual nos apresenta seu "Modelo para uma Universidade para o Século XXI", parte do pressuposto de que os sistemas universitários atuais estão "esgotados e ineficientes", garantindo-nos que:

O ponto fundamental é reconhecer que o cenário da globalização envolve os conceitos de $O$ mundo é plano: uma breve história do século XXI de Thomas I. Friedman, 2005, e dos conceitos do livro Ideals and Realities do Prêmio Nobel Abdus Salam, editado pelo ICTP, Trieste e pela Third World Academy of Sciences (TWAS, TRIESTE, ITALY). Minha visão é que a universidade para o séc. XXI deverá ser uma universi- 
dade internacional tendo a América Latina como seu foco principal, mas sem deixar de lado o "mundo plano", pois nesse caso sua missão estaria dentro de um cenário limitado por natureza da inseparabilidade do sistema complexo do que gosto de chamar a terceira cultura advinda do cenário do livro The two cultures de C. P. Snow (já de 1959!). Isto é a junção das humanidades com ciências, tecnologias e inovações.

Um e outro professor, como se pode deduzir, irrompem-se contra a hierarquia, autoridade e rigidez características das instituições de Ensino Superior burocratizadas, em favor da flexibilidade, atenção à estrutura e melhoria dos processos. Dos seus lugares de reformadores, forçam tais instituições a deslocar o foco das suas atividades para as necessidades dos cidadãos consumidores em vez das necessidades da burocracia. A palavra de ordem passa a ser funcionar melhor com custos menores, e a sua primeira etapa de realização é que os administradores passem a considerar as características dos usuários ou dos consumidores e dos concorrentes e entendam o que é preciso mudar (KETLL, 2009). A configuração de um espaço integrado de mobilidade acadêmica e educação superior no estado se desenvolve sob este marco e traz consigo o princípio segundo o qual "isoladamente nenhuma das estruturas organizacionais (ou institucionais) existentes consegue resolver grandes problemas" (KETLL, 2009, p. 87).

Esse irromper-se contra a hierarquia, autoridade e rigidez características das IES burocratizadas não é subjetivo. Ele é típico da revolução global pela reforma da administração pública e tem razões objetivas para a sua determinação, cuja gênese deve ser buscada na crise do processo sociometabólico do capital a partir de meados dos anos 1970 do século passado, quando as contradições do Estado de Bem-Estar Social expuseram "os limites absolutos das determinações mais internas do capital", revelando a sua baixa eficiência e a "assustadora ineficiência da extração do trabalho excedente, com imensas implicações para as perspectivas do próprio sistema do capital" (MÉSZÁROS, 2006, p. 103) ${ }^{10}$.

A materialização de uma política que integra alunos de Educação Superior matriculados na modalidade semipresencial (educação online) e alunos matriculados nos cursos presenciais é parte dessas reformas. A criação de um espaço integrado de mobilidade aca- dêmica e Educação Superior, porém, nasce como um campo de lutas de forças que se opõem.

\section{Espaço Integrado de Mobilidade Acadêmica e Educação Superior e contradições}

Poderíamos começar esta seção dando visibilidade às inúmeras críticas que são produzidas a respeito da criação de espaços integrados de mobilidade acadêmica e educação superior pelo mundo afora, mas isto tão somente nos levaria a reduzir a contradição inerente ao fenômeno que estamos estudando a "um mero feixe de enunciados que, por contrários, se excluem mutuamente, nuns casos, ou acabam, no fundo, por se equivaler, noutros casos" (MOURA, 1977, p. 151). E isto seria uma atitude idealista e de falsificação conforme a ideologia burguesa, totalmente contrária à atitude dialética que queremos preservar e desenvolver. Interessa-nos aqui somente a perspectiva dialética que gradualmente reflita o fundamento objetivo da contradição existente no fenômeno que estamos analisando.

Assim, inicialmente, cabe-nos questionar com radicalidade sobre a luta de forças opostas que subjaz à configuração do que estamos chamando de Espaço Integrado de Mobilidade Acadêmica e Educação Superior do Estado do Rio de Janeiro. Quais são estas forças e qual tem predominância, isto é, qual efetivamente determina sua configuração nas bases da Deliberação em tela, seu sentido ou orientação segundo formas mais ou menos acentuadas? Para responder a estas questões estamos convictos de que todo o real é contraditório; as contradições porém não são naturais, não estão dadas, e nem são insuperáveis; muito pelo contrário. Há razões objetivas, históricas, que as determinam. Duas expressões políticas nacionais citadas a seguir dão visibilidade a tais razões.

O ex-presidente Fernando Henrique Cardoso (2006, $15)^{11}$, um ícone do neoliberalismo no Brasil, que realizou extenso programa de privatização de grandes empresas públicas brasileiras e de flexibilização nas relações de trabalho (remuneração, tempo de trabalho, contratação do trabalhador, solução de conflito...), é francamente favorável à reforma do Estado "numa fase de reorganização tanto do sistema econômico, como também do próprio sistema político mundial”. 
Reformar o Estado em seus termos significa adaptá-lo às novas demandas do mundo contemporâneo, reduzir custos, cobrar resultados, superar os modelos burocráticos do passado, orientá-lo por valores gerados pela própria sociedade (de mercado, diga-se a propósito).

Bresser Pereira (2006, p. 21) ${ }^{12}$, ex-ministro da Administração Federal e Reforma do Estado no primeiro governo de FHC, de igual modo, defende a reforma do Estado. Em suas próprias palavras: "para podermos ter uma administração pública moderna e eficiente, compatível com o capitalismo competitivo em que vivemos, seria necessário flexibilizar o estatuto dos servidores públicos de modo a aproximar os mercados de trabalho público e privado".

Poderíamos ainda trazer outros partidários da revolução global de reforma da administração pública, $e$ também saturar o nosso objeto de historicidade, mas correríamos o risco de cansar o nosso leitor. Além da vasta literatura sobre o mesmo ${ }^{13}$, consideramos, entretanto, que as palavras de FHC e Bresser Pereira sejam suficientes para evidenciar as forças presentes de modo subjacente, ou não, ao campo de luta de forças opostas que se configura como Espaço Integrado de Mobilidade Acadêmica e Educação Superior do Estado do Rio de Janeiro, e qual tem predominância. Enganamo-nos se simplesmente opomos a estruturação de um Estado Gerencial como resposta à crise do Estado que emergiu na segunda metade do século XX a um Estado patrimonialista, burocrático, autoritário e rígido. Os dois polos da contradição presente no fenômeno mobilidade acadêmica e integração de alunos matriculados nas modalidades presenciais e semipresenciais (educação online) não são outros senão o capitalismo competitivo, orientado para a expansão e movido pela acumulação, e o trabalho dos profissionais da educação superior. Trata-se, pois, como nos diz Mészáros, da estruturação de novas formas de controle totalizador "à qual tudo o mais, inclusive seres humanos, deve se ajustar, e assim provar sua 'viabilidade produtiva', ou perecer, caso não consiga se adaptar". Um controle que o capital impõe sobre o sistema de educação superior para torná-lo mais eficaz e produtivo.

Para avançar em nossa reflexão, é indispensável destacar quais mediações estão presentes, ou quais são as mais visíveis neste campo de lutas. Vale aqui lembrar que estamos empregando a categoria mediação como categoria do real, como "especificidade histórica do fenômeno" e que se situa "no campo dos objetos problematizados nas suas múltiplas relações no tempo e espaço, sob ação de sujeitos sociais" (CIAVATTA, 2001, p. 141-142) ${ }^{14}$. É a subjetividade da mediação que nos permite entender por que o fenômeno que estamos estudando se configura de um modo e não de outro, assim como as determinações que o levam a ser assim.

\section{Capital Social, neoinstitucionalismo e Estado gerencial \\ 4.1. Capital social \\ O capital social é uma mediação importante pre-} sente no fenômeno, apesar de não ter ainda uma definição consensual. Diversos teóricos citados por Kliksberg (2002) ${ }^{15}$ tendem, entretanto, a defini-lo como resultante:

- Do "grau de confiança existente entre os atores sociais de uma determinada sociedade, pelas normas de comportamento cívico e pelo nível de associativismo" (ROBERT PUTNAM, 1994);

- "Do grau de integração social de um indivíduo, com sua rede de contatos sociais, implica relações, expectativa de reciprocidade, comportamentos confiáveis; é um bem coletivo" (JAMES COLEMAN,1990);

- Da "coesão social, com identificação com as formas de governo, com expressões culturais e comportamentos sociais que tornam a sociedade mais coesiva, mais forte que a simples soma dos indivíduos (...) os arranjos institucionais horizontais têm um impacto positivo na geração de redes de confiança, bons governos e eqüidade social. O capital social desempenha um papel importante ao estimular a solidariedade e superar as falhas do mercado através de ações coletivas e do uso comunitário de recursos" (STEPHAN BAAS, 1997);

- E dos "valores e atitudes que influenciam o modo como as pessoas se relacionam entre si. Inclui confiança, normas de reciprocidade, atitudes e valores que ajudam as pessoas a transcender relações conflituosas e competitivas para conformar relações de cooperação e ajuda mútua" (KENNETH NEWTON, 1997).

Examinando com atenção essas definições encontramos nelas diversos pontos que as aproximam, 
particularmente ao ressaltarem determinados valores: confiança, reciprocidade, associativismo, cooperação e ajuda mútua, e solidariedade. Kliksberg, com base nessas definições e nesses valores, assume que o desenvolvimento do Estado deve ser "um processo essencialmente amigável, centrado em ajudar os outros e a si", para desenvolver novas formas de gerenciamento dos serviços públicos que possam conferir às pessoas mais capacidades para ajudar a si mesmas e aos outros. Daí aponta a imperiosidade de se redesenhar o Estado, suas instituições e formas de gestão com a adoção de técnicas modernizantes para facilitar e promover o desenvolvimento social. Em sua ótica os processos de reforma das instituições devem resultar na identificação precisa das suas necessidades prioritárias, na criação de fluxo de informações úteis, na aplicação de ideias inovadoras criadas pela comunidade e na avaliação contínua "do andamento do programa de modo a constituir ainda um preventivo quase não superável diante da possibilidade de corrupção".

\subsection{Neoinstitucionalismo}

Nosso esforço metodológico nos incumbe ainda o exame do neoinstitucionalismo como mediação igualmente importante. Cada uma das formas históricas que assume (neoinstitucionalismo histórico, de escolha racional, e sociológico) precipita-se contra o que considera como indivíduos isolados, egoístas, remetidos a si no interior das instituições.

Em sua primeira versão acusa os indivíduos de desenvolver cálculos estratégicos, somente buscando maximizar seus rendimentos no interior das instituições e locupletando-se do regime de estabilidade e das expectativas de futuro que são oferecidas. A seguinte censura-os por compartilharem certas preferências e gostos, e de se beneficiarem de modo utilitarista das possibilidades que a instituição oferece, maximizando as suas preferências pessoais; reconhece no entanto que são os acordos que fazem entre si frente aos benefícios oferecidos que levam as instituições à prosperidade. A última não apenas reprime os cálculos estratégicos individuais, como vigorosamente orienta as reformas das instituições de modo a se modernizarem a partir de processos de discussão, democráticos e transparentes com a participação de todos (HALL; TAYLOR, 2003).

A estruturação desse espaço de mobilidade acadêmica e integração da educação superior no Estado do Rio de Janeiro, obviamente, visa produzir capital social a partir de instituições modernizadas, flexíveis, confiáveis e com profissionais dotados de uma mentalidade voltada para servir aos consumidores. A pesquisa que estamos realizando, tendo como objeto a avaliação das instituições de educação superior (IES) conforme as determinações do Sistema Nacional de Avaliação da Educação Superior (SINAES), vem nos demonstrando a agilidade da reforma da universidade brasileira nestes termos, mas com fortes implicações no apagamento dos indivíduos e das suas subjetividades, subsumindo-os ao coletivo $e$ aos cânones essenciais dos planos $e$ metas de desenvolvimento da IES (GAMA, 2009) ${ }^{17}$.

\subsection{Estado gerencial}

O Estado brasileiro, desde 1995, de fato vem sendo reformado com base na proposta de administração pública gerencial para superar definitivamente as formas de patrimonialismo e de administração burocratizada - controle hierárquico e formalista dos procedimentos - e fazer frente às demandas postas pela globalização da economia, tornando-se um Estado competitivo.

O principal mentor dessa reforma no Brasil é o ex-ministro da Administração Federal e Reforma do Estado, Luis Carlos Bresser Pereira. No livro que organiza com Peter Spink (2006) ${ }^{18}$, apresenta-nos em capítulo próprio (PEREIRA, 2006) ${ }^{19}$ as características básicas da administração pública gerencial. A principal delas é a administração do Estado Gerencial ter sua orientação voltada para o cidadão, suas necessidades e perspectivas como consumidor de serviços. Outras são a obtenção de resultados, concessão de grau limitado de confiança aos funcionários públicos, incentivo à criatividade e à inovação, descentralização dos serviços, controles rígidos sobre os desempenhos com base em indicadores. Ketll (2006, p. 77) muito claramente, nos informa que, por detrás do impulso de organizar Estados e governos que funcionem melhor, está sempre presente a ideia de se criar "um Estado mais barato e mais eficiente", assim como a de coordenar os organismos públicos, "que 
pareciam mais interessados em promover seus próprios negócios do que em servir aos cidadãos".

A construção de um espaço de mobilidade acadêmica e de integração da educação superior, aqui ou alhures, como se pode perceber com a interveniência dessas mediações, apresenta-se como uma nova forma de reorganizar e gerenciar o funcionamento das instituições do Estado, incluindo entre elas as de educação superior de ensino presencial e semipresencial. As apostas estão na capacidade desse novo arranjo horizontal ter impacto positivo na geração de redes de ensino públicas, confiáveis, solidárias, eficientes $e$ promotoras de maior equidade social, colocando os cursos oferecidos a serviço dos alunos-consumidores.

\section{Considerações finais}

O ponto de vista que assumimos ao longo desta análise é que em períodos de crise do processo sociometabólico do capital, do ponto de vista do capital se torna cada vez mais necessária a subordinação do trabalho vivo, natureza, ciência e tecnologia. A integração do sistema de educação superior semipresencial e presencial no estado do Rio de Janeiro é coerente com esse processo em curso de reforma do Estado. É um novo arranjo interinstitucional capaz inclusive de fazer frente ao déficit crônico de professores concursados e de incidir sobre a contratação de substitutos. A mobilidade acadêmica pode promover o fluxo de alunos para as disciplinas ministradas por professores concursados, seja em regime presencial ou semipresencial e enxugar o quadro de profissionais de educação superior.

Claro está que não pretendemos negar a importância de integrar as modalidades de ensino semipresenciais e presenciais das instituições públicas de educação superior no Estado do Rio de Janeiro e também no Brasil. Tampouco pretendemos minimizar a utilização de novas tecnologias para o oferecimento de novas disciplinas online. Entendemos que um espaço integrado de educação superior, com um sistema de mobilidade acadêmica que permita aos alunos semipresenciais e presenciais buscar os conhecimentos mais apurados onde estiverem sendo disponibilizados, tem grande valores sobretudo lembrando sempre que a educação que pode vir do professor para o aluno é muito melhor, rica e emocionante que aquela encontrada na tela de um computador.

Esse espaço integrado, ora em processo de formação, não pode, no entanto, abrir mão de mais meios, recursos e professores bem preparados e entregues ao ensino, pesquisa e extensão, e de alunos desejosos de saber. Menos ainda pode abstrair a criatividade e a subjetividade dos professores, pesquisadores e funcionários técnico-administrativos: cada um precisa dedicar-se ao seu próprio tempo de investigação e reflexão sem que se sinta oprimido pelos objetivos, metas e cronogramas institucionais como se tivesse que se tornar consciência da instituição $e$ agir sincronizadamente. O engessamento dos indivíduos, criativos e em processos de desenvolvimento de suas subjetividades, mesmo sendo um dos objetivos do neoinstitucionalismo, é uma perversidade porquanto a individualização precisa ser vista como um processo que se realiza e se consuma no e pelo viver deveniente num sistema relacional determinado de sociabilidade.

É nesses termos que pensamos o que está em construção, entendendo que um espaço de mobilidade acadêmica e integração do sistema de educação superior semipresencial e presencial deve constituir-se como espaço de desenvolvimento do conhecimento $e$ de comunicação desinteressada situado bem longe do pragmatismo gerencial-mercantil, como nos recomenda Carlos Paris (2009).

Reduzi-lo a esse pragmatismo com intuito de reduzir custos, quadros de funcionários e ter melhores indicadores de produtividade para mais produzir capital social será uma lástima. 


\section{Notas:}

${ }^{1}$ O Consórcio CEDERJ/FUNDAÇÃO CECIERJ está ligado ao Governo do Estado do Rio de Janeiro e engloba seis universidades públicas sediadas no Estado: Universidade do Estado do Rio de Janeiro - UERJ; Universidade Estadual do Norte Fluminense Darcy Ribeiro - UENF; Universidade Federal do Estado do Rio de Janeiro - UNIRIO; Universidade Federal do Rio de Janeiro - UFRJ; Universidade Federal Fluminense - UFF; Universidade Federal Rural do Rio de Janeiro - UFRRJ.

${ }^{2}$ KOSIK, K. Dialética do concreto. Rio de Janeiro: Paz e Terra, 1976.

${ }^{3}$ MOURA, J. B. Totalidade e contradição acerca da dialética. Lisboa: Livros Horizonte, 1977.

${ }^{4}$ KETTL, Donald. F. A revolução global: reforma da administração do setor público. In PEREIRA, L. C. Bresser; SPINK, P. Kevin (Orgs.). Reforma do Estado e Administração pública gerencial. Rio de Janeiro: Editora FGV, 2006.

${ }^{5}$ SPINELLI, L. Educação - Enem aumentará mobilidade. Recife: JORNAL DO COMMERCIO , edição de 11.5.2009.

${ }^{6}$ ANDIFES (Associação Nacional dos Dirigentes das Instituições Federais de Ensino Superior). Mobilidade Acadêmica. Portal Andifes. www.andifes.org.br. Acessado em janeiro de 2010.

${ }^{7}$ MERCOSUR EDUCATIVO. Mobilidade. Portal Mercosur Educativo. Disponível no site: www.sic.inep.gov.br. Acessado em janeiro de 2010.

${ }^{8}$ OLIVEIRA, Gilvan Müller de. Entrevista ao Informativo CI-UNILA. Informativo da Comissão de Implantação da Universidade Federal da Integração Latino-Americana ( ${ }^{\circ}$ 4, Abril de 2009). Disponível no site www.iesalc.unesco.org.ve. Acessado em janeiro de 2010.

${ }^{9}$ MASCARENHAS, Sérgio. Modelo para uma universidade para o século XXI. Informativo da Comissão de Implantação da Universidade Federal da Integração Latino-Americana ( $\mathrm{N}^{\circ} 4$, Abril de 2009). Disponível no site www.iesalc.unesco.org.ve. Acessado em janeiro de 2010.

${ }^{10}$ MÉSZÁROS, Istvan. Para além do capital. São Paulo: Boitempo, 2006.

${ }^{11}$ CARDOSO, Fernando Henrique. Reforma do Estado. In PEREIRA, L. C. Bresser; SPINK, P. Kevin (Orgs.). Reforma do Estado e Administração pública gerencial. Rio de Janeiro: Editora FGV, 2006.

${ }^{12}$ PEREIRA, L. C. Bresser. Gestão do setor público: estratégia e estrutura para um novo estado. In PEREIRA, L. C. Bresser; SPINK, P. Kevin (Orgs.). Reforma do Estado e Administração pública gerencial. Rio de Janeiro: Editora FGV, 2006.

${ }^{13}$ Para maior aprofundamento ler, por exemplo, Mészáros, Istvan: Para além do capital. São Paulo: Boitempo, 2006; Paulani, Leda. Modernidade e discurso econômico. São Paulo: Boitempo, 2005; Chesnais, François (Coord.). A mundialização financeira: gênese, custos e riscos. São Paulo: Xamã, 1998.

${ }^{14}$ CIAVATTA, Maria. O conhecimento histórico e o problema teórico-metodológico das mediações. In FRIGOTTO, G; CIAVATTA, M. Teoria e Educação no Labirinto do Capital, Petrópolis: Vozes, 2001.

${ }^{15}$ KLIKSBER, Bernardo. Capital social e cultura: as chaves esquecidas do desenvolvimento. [Rio de Janeiro]: PREAL, [2002]. Disponível no site: www.inep.gov.br/PESQUISA/BBE-ONLINE/obras.asp?autor=KLIKSBERG,+BERNARDO . Acessado em janeiro de 2010.

${ }^{16}$ HALL, P. A; TAYLOR, R. C. R. As três versões do neoinstitucionalismo. Lua Nova, Revista de Cultura e Política, nº 58, 2003.

${ }^{17}$ GAMA, Z. J. Avaliação das instituições públicas de ensino superior: direções e interesses subjacentes (Relatório de Pesquisa). Rio de Janeiro: UERJ/PROCIÊNCIA, 2009.

${ }^{18}$ PEREIRA, L. C. B; SPINK, P. Kevin. Reforma do Estado e administração pública gerencial. Rio de Janeiro: Editora FGV, 2006.

${ }^{19}$ PEREIRA, L. C. B. Reforma do Estado. In PEREIRA, L. C. B; SPINK, P. Kevin. Reforma do Estado e administração pública gerencial. Rio de Janeiro: Editora FGV, 2006.

${ }^{20}$ PARIS, Carlos. La universidad ante Bolonia. In La Cara Fosca Del Pla Bolonya: Contra La Universitat S/A - en defensa de La Universitat pública. Barcelona: Edicions Bellaterra, 2009. 


\section{Referências bibliográficas:}

ANDIFES (Associação Nacional dos Dirigentes das Instituições Federais de Ensino Superior). Mobilidade Acadêmica. Portal Andifes. www.andifes.org.br . Acessado em janeiro de 2010.

CARDOSO, Fernando Henrique. Reforma do Estado. In PEREIRA, L. C. Bresser; SPINK, P. Kevin (Orgs.). Reforma do Estado e Administração pública gerencial. Rio de Janeiro: Editora FGV, 2006.

CIAVATTA, Maria. O conhecimento histórico e o problema teórico-metodológico das mediações. In FRIGOTTO, G; CIAVATTA, M. Teoria e Educação no Labirinto do Capital, Petrópolis: Vozes, 2001.

GAMA, Z. J. Avaliação das Instituições Públicas de Ensino Superior: direções e interesses subjacentes (Relatório de Pesquisa). Rio de Janeiro: UERJ/PROCIÊNCIA, 2009.

HALL, P. A; TAYLOR, R. C. R. As três versões do neoinstitucionalismo. Lua Nova, Revista de Cultura e Política, n 58, 2003.

KETTL, Donald. F. A revolução global: reforma da administração do setor público. In PEREIRA, L. C. Bresser; SPINK, P. Kevin (Orgs.). Reforma do Estado e Administração pública gerencial. Rio de Janeiro: Editora FGV, 2006.

KLIKSBERG, Bernardo. Capital social e cultura: as chaves esquecidas do desenvolvimento. [Rio de Janeiro]: PREAL, [2002].Disponívelnosite:www.inep.gov.br/PESQUISA/BBEONLINE/obras.asp?autor $=$ KLIKSBERG,+ BERNARDO. Acessado em janeiro de 2010

KOSIK, K. Dialética do Concreto. Rio de Janeiro: Paz e Terra, 1976;

MASCARENHAS, Sérgio. Modelo para uma universidade para o Século XXI. Informativo da Comissão de Implantação da Universidade Federal da Integração Latino-Americana ( $N^{\circ} 4$, Abril de 2009). Disponível no site www.iesalc.unesco.org.ve . Acessado em janeiro de 2010.
MERCOSUR EDUCATIVO. Mobilidade. Portal Mercosur Educativo. Disponível no site: www.sic.inep. gov.br. Acessado em janeiro de 2010.

MÉSZÁROS, Istvan. Para além do capital. São Paulo: Boitempo, 2006.

MOURA, J. B. Totalidade e Contradição Acerca da Dialética. Lisboa: Livros Horizonte, [1977].

OLIVEIRA, Gilvan Müller de. Entrevista ao Informativo CI-UNILA. Informativo da Comissão de Implantação da Universidade Federal da Integração Latino-Americana ( $\mathrm{N}^{\circ} 4$, Abril de 2009). Disponível no site www.iesalc. unesco.org.ve. Acessado em janeiro de 2010.

PARIS, Carlos. La universidad ante Bolonia. In La Cara Fosca Del Pla Bolonya: Contra La Universitat S/A - en defensa de La Universitat pública. Barcelona: Edicions Bellaterra, 2009.

PEREIRA, L. C. B. Reforma do Estado. In PEREIRA, L. C. B; SPINK, P. Kevin. Reforma do Estado e Administração pública gerencial. Rio de Janeiro: Editora FGV, 2006.

PEREIRA, L. C. B; SPINK, P. Kevin. Reforma do Estado e Administração pública gerencial. Rio de Janeiro: Editora FGV, 2006.

PEREIRA, L. C. Bresser. Gestão do setor público: estratégia e estrutura para um novo estado. In PEREIRA, L. C. Bresser; SPINK, P. Kevin (Orgs.). Reforma do Estado e Administração pública gerencial. Rio de Janeiro: Editora FGV, 2006.

SPINELLI, L. Educação-Enem aumentará mobilidade. Recife: Jornal do Commercio, edição de 11.05.2009 